\title{
Deep Vein Thrombosis Revealing Prostate Cancer about a Case in the Cardiology Department of the Ignace Deen National Hospital in Conakry
}

\author{
Ibrahima Sory Barry ${ }^{1 *}$ (), Hadj Yaya El Balde ${ }^{1}$, Diarra Koivogui ${ }^{1}$, Abdoulaye Camara ${ }^{1}$, \\ Aly Samoura1, Mamadou Bassirou Bah', Mamadou Aliou Balde1, Alpha Kone², \\ Ibrahima Sory Sylla1, Souleymane Diakite'3, Moussa Kourouma1, Kokoulo Koivogui', \\ Mariam Beavogui', Mamadou Dadhi Balde1, Mamadi Conde1 \\ ${ }^{1}$ Cardiology Service of Ignace Deen National Hospital, Conakry, Guinea \\ ${ }^{2}$ Cardiology Department of DONKA National Hospital, Conakry, Guinea \\ ${ }^{3}$ Military Health Service at the Battalion of the Headquarters Camp Almamy Samory TOURE, Conakry, Guinea \\ Email: ‘issobarry@yahoo.fr, yaya_balde@yahoo.fr, koivoguidiara@gmail.com, mariboudou@gmail.com, \\ samouraaly@gmail.com,bachirov80@yahoo.fr, alioubalde800@yahoo.fr, alafekone@gmail.com,ibsosyl@yahoo.fr, \\ diakitesouleymane49@yahoo.fr, doumbouyamoussa2550@gmail.com, koklokoivogui@gmail.fr, \\ beavoguimariama7@gmail.com,profdadhi@gmail.com,condemamadi54@gmail.com
}

How to cite this paper: Barry, I.S., El Balde, H.Y., Koivogui, D., Camara, A., Samoura, A., Bah, M.B., Balde, M.A., Kone, A., Sylla, I.S., Diakite, S., Kourouma, M., Koivogui, K., Beavogui, M., Balde, M.D. and Conde, M. (2020) Deep Vein Thrombosis Revealing Prostate Cancer about a Case in the Cardiology Department of the Ignace Deen National Hospital in Conakry. World Journal of Cardiovascular Diseases, 10, 608-613.

https://doi.org/10.4236/wjcd.2020.108059

Received: April 24, 2020

Accepted: August 28, 2020

Published: August 31, 2020

Copyright $\odot 2020$ by author(s) and Scientific Research Publishing Inc. This work is licensed under the Creative Commons Attribution International License (CC BY 4.0).

http://creativecommons.org/licenses/by/4.0/ (c) (i) Open Access

\begin{abstract}
Introduction: Deep vein thrombosis is a frequent disease, its origin is most often multifactorial. Venous thromboembolic disease (MVTE) and cancer are two frequently entangled pathologies. Here we report the diagnosis of deep vein thrombosis that discovered prostate cancer in an 88-year-old Guinean man. On clinical examination, there was a painful and hot swelling of the right leg, an absence of sloshing of the calf, a positive sign of Homans. The digital rectal examination revealed an enlarged prostate with an irregular surface. Cardiopulmonary auscultation was normal. The electrocardiogram showed a regular sinus rhythm at 65 cycles/min, with no sign of enlarged cavities or conduction disturbance. Venous Doppler ultrasound of the lower limbs showed the presence of an extensive acute deep venous thrombosis of the right sural vein extended to the popliteal and to the homolateral deep femoral. The reino-vesico-prostatic ultrasound concluded in a heterogeneous prostatic hypertrophy with projection of a median lobe associated with a bladder of fight with an important post voiding residue evaluated at $170 \mathrm{ml}$; the rate of specific antigen of the prostate PSA was at $84.87 \mathrm{ng} / \mathrm{ml}$. The pathology analysis made after a prostate biopsy puncture concluded with an adenocarcinoma with a Gleason score of 3. Conclusion: The association of
\end{abstract}


venous thromboembolic disease (MVTE) and neoplasia is frequent. The existence of active cancer in a patient is a known risk factor for MVTE and, conversely, the discovery of a first episode of deep vein thrombosis (DVT) or pulmonary embolism (PE) may be the mode of revelation of cancer.

\section{Keywords}

Deep Vein Thrombosis, Prostate Cancer, Elderly, Conakry

\section{Introduction}

Venous thrombosis is a frequent disease; its origin is most often multifactorial. Its incidence is variable; in France a recent work carried out in Brest found an incidence of 1.24 of venous thrombosis per 1000 people [1]. In the United States Anders finds an incidence of 0.48 event per 100 inhabitants [2].

Venous thromboembolic disease (MVTE) and cancer are two frequently entangled pathologies. MVTE is likely to complicate the development of nearly $10 \%$ of cancer patients and is particularly difficult to manage [3]. Conversely, cancer is present in almost $20 \%$ of patients with MVTE and it is even likely to be the first sign of tumor pathology [4].

Cancer patients very often combine several acquired risk factors for MVTE: bed rest, surgery, immobilization, extrinsic venous compression, etc., certain specific cancer treatments, such as chemotherapy [5].

In Guinea, a study carried out in 2016 found 40 cases of venous thrombosis, i.e. $13 \%$ of the hospitalization rate [6]. Many factors are involved in the occurrence of venous thrombosis among which we have cancers, hemopathies; the frequency of thrombosis in cancer patients is 5 - 10 [1] [7]. The objective of this study was to report a case of deep vein thrombosis of the right lower limb linked to prostate cancer, to underline the importance of systematic screening for prostate cancer before a deep vein thrombosis especially in the elderly.

\section{Observation}

The patient was an 88-year-old former driver admitted to the cardiology department of the Ignace Deen national hospital for a painful swelling of the right leg, a fever, and low back pain. This symptomatology had been evolving for two weeks. In his personal history, we find a notion of herniated disc evolving for 7 years and having led to a sensory and motor deficit of the lower limbs. Note that the patient is neither hypertensive, diabetic, nor smoking. The initial clinical examination found a fairly good general condition, a BP equal to $120 / 80 \mathrm{mmHg}$, a heart rate of 100 beats, a $\mathrm{SaO}_{2}$ at $98 \%$ in ambient air, a swelling of the painful, hot right leg with absence calf sloshing and a positive Homans sign. The pelvic feel reveals an increase in the volume of the prostate, with an irregular surface. Cardiopulmonary auscultation was normal. The electrocardiogram showed a 
regular sinus rhythm at 65 cycles/min, with no sign of enlarged cavities or conduction disturbance. Venous Doppler ultrasound of the lower limbs showed the presence of an extensive acute deep venous thrombosis of the sural vein extended to the popliteal and the deep femoral. The reino-vesico-prostatic ultrasound concluded in a heterogeneous prostatic hypertrophy with projection of a median lobe associated with a bladder of fight with a significant post voiding residue evaluated at $619 \mathrm{ml}$, the rate of specific antigen of prostate PSA was at $84.87 \mathrm{ng} / \mathrm{ml}$. The pathology analysis made after a prostate biopsy puncture concluded with an adenocarcinoma with a gleason score of 3 .

The patient was treated with effective anticoagulation and analgesics. The evolution was favorable with a clear regression of the swelling of the right leg. $\mathrm{He}$ was referred to urology for the surgical management of the prostate (Figures 1-3).

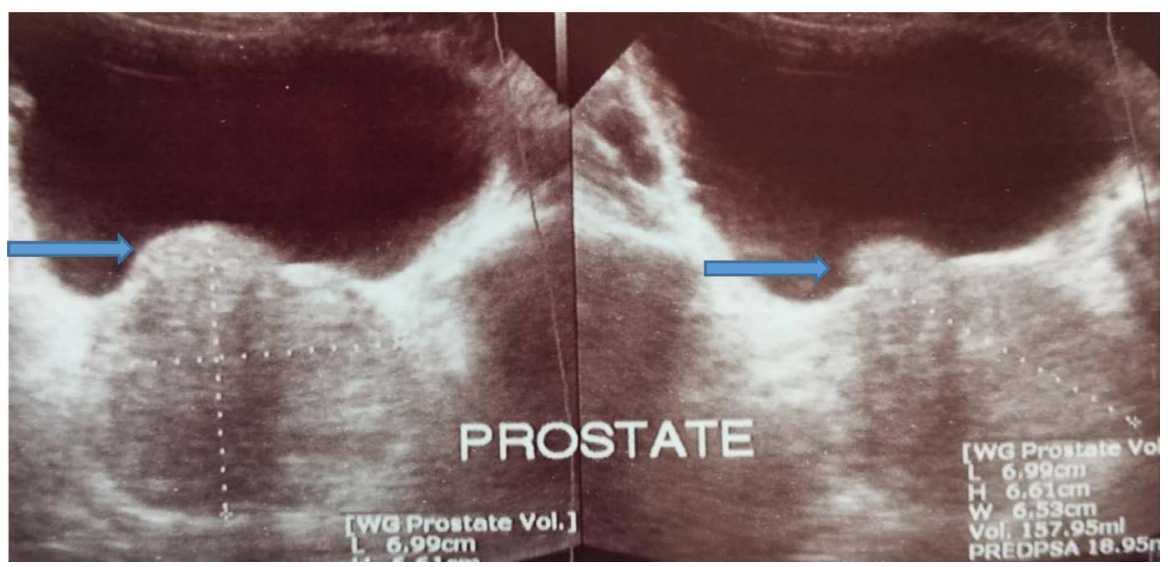

Figure 1. Ultrasound showing heterogeneous prostatic hypertrophy with a protrusion of the median lobe.

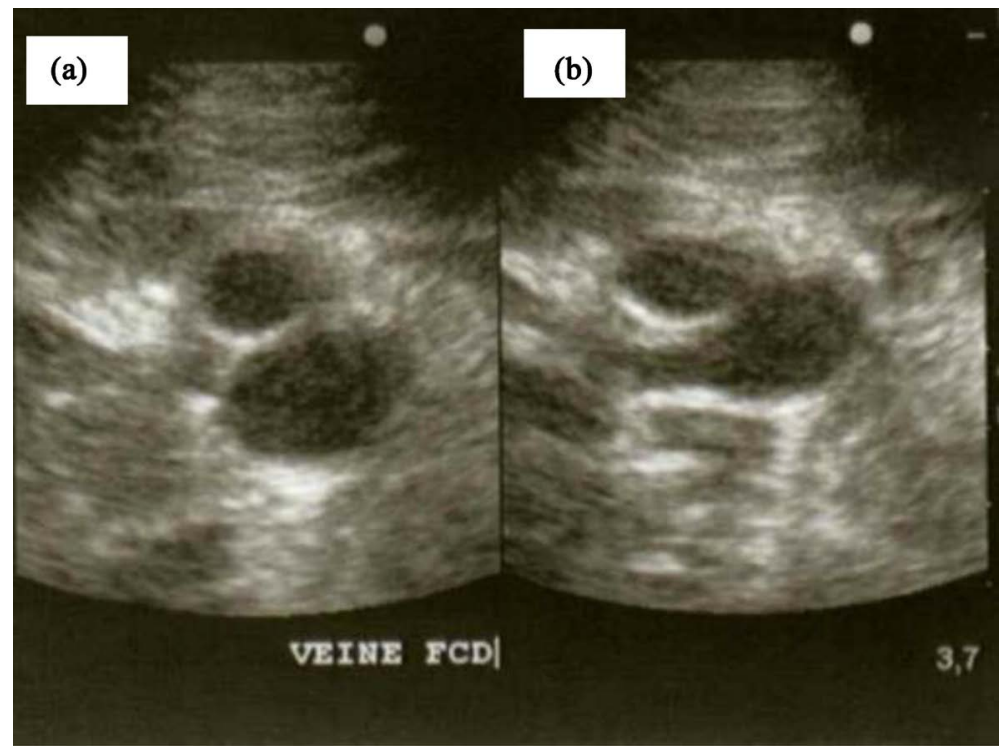

Figure 2. Venous Doppler ultrasound of the lower limbs with (a) and without compression (b). 


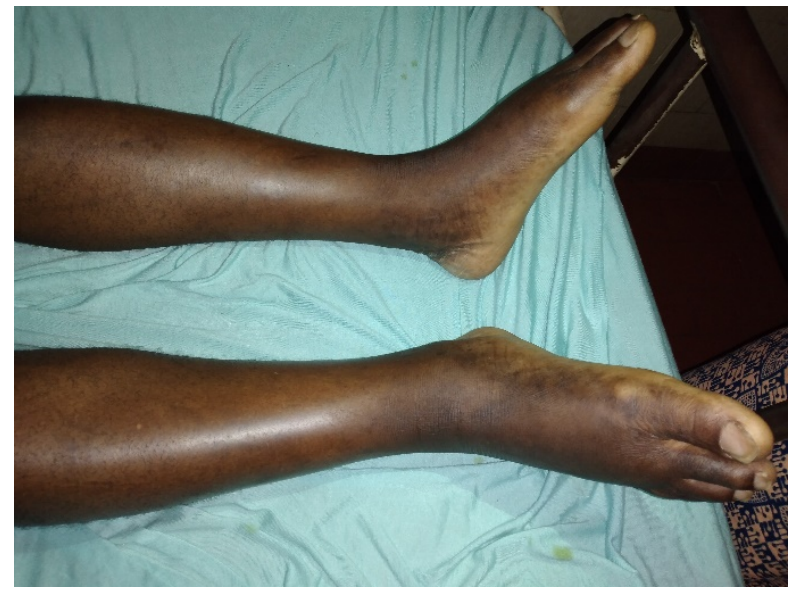

Figure 3. Swelling of the right leg following an acute deep vein thrombosis.

\section{Discussion}

As reported in this clinical case, the association between cancer and the occurrence of venous thromboembolic disease has been known since the $19^{\text {th }}$ century. There are many arguments for the causal nature of this association. This association seems independent of the other thromboembolic risk factors, it is reversible and the thromboembolic risk disappears with the cure of the cancer [8]. Thus, in a North American study of the case control type in the population, cancer was found in 142 patients out of the 625 cases of MVTE included (23\%), compared to 22 patients out of 625 controls (3.5\%) matched for the age and sex: the odds ratio for the association between cancer and MVTE was $7.7 \%$ to $95 \%$. This can be interpreted as follows: the presence of cancer is associated with a sevenfold risk of MVTE [9].

As presented in this clinical case, advanced age is both a risk factor for venous thromboembolic disease [10] and prostate cancer after 50 years [11].

The revealing circumstance of prostate cancer in our patient was deep vein thrombosis of the right lower limb. In the literature, the revealing circumstances of prostate cancer are very variable: the symptoms are represented by urination disorders such as urgency, pollakiuria, dysuria, acute retention of urine, but sometimes by symptoms related to local compression as a unilateral edema of a lower limb [12] [13].

The biopsy revealed an adenocarcinoma which in agreement with the data of the literature which reports that the adenocarcinomas seem to be more providers of venous thromboembolic disease than the squamous cell carcinomas as evidenced by a Dutch study where the incidence of thrombosis was estimated at 537 patients included after diagnosis of non-small cell lung cancer [14].

\section{Conclusion}

There is a strong association between cancer and venous thromboembolic disease, with a risk multiplied by approximately seven to develop venous thromboembolic disease in cancer patients compared to free patients. It can be the first 
clinical manifestation of cancer. Routine pelvic examination is necessary in any patient with deep vein thrombosis of the lower limbs.

\section{Conflicts of Interest}

The authors declare no conflicts of interest regarding the publication of this paper.

\section{References}

[1] Oger, E. (2000) Incidence of Venous Thromboembolism: A Community-Based Study in Western France. EPI-GETBP Study Group. Groupe d'Etude de la Thrombose de Bretagne Occidentale. Thrombosis and Haemostasis, 83, 657-660.

[2] Anderson, F.A., Wheeler, H.B., Goldberg, R.J., Hosmer, D.W., Patward-han, N.A., Jovanovic, B., et al. (1991) A Population-Based Perspective of the Hospital Incidence and Case-Fatality Rates of Deep Vein Thrombosis and Pulmonary Embolism. The Worcester DVT Study. Archives of Internal Medicine, 151, 933-938.

https://doi.org/10.1001/archinte.151.5.933

[3] Chew, H.K., Wun, T., Harvey, D., et al. (2006) Incidence of Venous Thromboembolism and Its Effect on Survival among Patients with Common Cancers Archives of Internal Medicine, 166, 458-464. https://doi.org/10.1001/archinte.166.4.458

[4] Goldhaber, S.Z., Visani, L. and De Rosa, M. (1999) Acute Pulmonary Embolism: Clinical Outcomes in the International Cooperative Pulmonary Embolism Registry (ICOPER). The Lancet, 353, 1386-1389. https://doi.org/10.1016/S0140-6736(98)07534-5

[5] Khorana, A.A., Kuderer, N.M., Culakova, E., Lyman, G.H. and Francis, C.W. (2008) Development and Validation of a Predictive Model for Chemo-Therapy-Associated Thrombosis. Blood, 111, 4902-4907. https://doi.org/10.1182/blood-2007-10-116327

[6] Sylla, D., et al. (2017) Thrombose veineuse des membres inférieurs à propos de 40 cas colligés à conakry. Cardiologie Tropicale, 150, 1-5.

[7] Ginsberg, J.S., Greer, I. and Hirsh, J. (2001) Use of Antithrombotic Agents during Pregnancy. Chest, 119, 122S-131S. https://doi.org/10.1378/chest.119.1_suppl.122S

[8] Descourt, R., et al. (2008) Place du cancer parmi les facteurs de risqué de la maladie thromboembolique veineuse. Pathologie Biologie, 56, 178-183. https://doi.org/10.1016/j.patbio.2007.12.008

[9] Heit, J.A., Silverstein, M.D., Mohr, D.N., Petterson, T.M., O’Fallon, W.M. and Melton, L.J.J. (2000) Risk Factors for Deep Vein Thrombosis and Pulmonary Embolism: A Population-Based Case-Control Study. Archives of Internal Medicine, 160, 80915. https://doi.org/10.1001/archinte.160.6.809

[10] Cogo, A., Bernardi, E., Prandoni, P., Girolami, A. and Noventa, F. (1994) Acquired Risk Factors for Deep-Vein Thrombosis in Symptomatic Outpatients. Archives of Internal Medicine, 154, 164-168. https://doi.org/10.1001/archinte.1994.00420020066008

[11] Meikle, A.W. and Smith, J.A. (1990) Epidemiology of Prostate Cancer: Early Detection and Treatment of Localized Carcinoma of the Prostate. Urologic Clinics of North America, 17, 709-718.

[12] Sctoffel, F. and Gasser, T.C. (1999) General Features and Strategy in the Diagnosis of Prostatic Carcinoma. Annali Italiani di Chirurgia, 70, 657-663.

[13] Fourmier, G., Valeri, A., Mangin, P. and Cussenot, O. (2004) Cancer de la prostate. Diagnostic et biland'extension. Annales d Urologie, 38, 207-224. 
https://doi.org/10.1016/j.anuro.2004.06.003

[14] Blom, J.W., Osanto, S. and Rosendaal, F.R. (2004) The Risk of a Venous Thrombotic Event in Lung Cancer Patients: Higher Risk for Adenocarcinoma than Squamous Cell Carcinoma. Journal of Thrombosis and Haemostasis, 2, 1760-1765.

https://doi.org/10.1111/j.1538-7836.2004.00928.x 